\title{
A systematic approach to risk reduction measures in the Norwegian offshore oil and gas industry
}

\author{
A. Sevcik \& O. T. Gudmestad \\ University of Stavanger, Norway
}

\begin{abstract}
The term 'safety barriers' refers to the measures used in the various riskassessment methods to reduce the likelihood and limit the consequences of hazardous events. An industry consensus is yet to be reached with regard to the boundaries and classification of safety barriers. The wide variability of work processes and physical systems that can be classified as barriers and the complex interactions between them means that they are challenging to identify. As such, a holistic view is required in order to foster adequate comprehension. The Petroleum Safety Authority Norway (PSA) focuses on maintaining a high level of health, environment, and safety awareness within the petroleum activities on the Norwegian Continental Shelf (NCS). The implementation of safety barriers has been a key safety principle in the PSA regulations for more than 10 years to guide the Norwegian oil and gas industry. The PSA constantly underlines the need for the risk picture to be clear and understandable with links and connections between related elements. This paper intends to provide some practical thoughts on how the boundaries for terms such as 'barrier', 'barrier element', 'barrier system' and 'function' can be determined. We will systemize existing knowledge and connect separate work processes into a unified system that will present barriers in a structured way, thus enabling adequate maintenance and follow-up of the barriers during their lifecycle. We intend to provide clarifications such that companies can manage and meet PSA regulations more precisely and efficiently.

Keywords: safety barrier, safety critical element, defence-in-depth, risk measure, safety management, offshore safety.
\end{abstract}




\section{Introduction}

The broad literature survey presented by Sklet [1] reveals that a wide variety of different approaches and terms are used to describe and systemize barriers as risk-reducing measures. The author states that "different terms with similar meanings (barrier, defence, protection layer, safety critical element, safety function, etc.) have been used crosswise between industries, sectors, and countries" and claims that "it is also difficult for the PSA to manage the regulations without a clear definition and delimitation of the concept". The importance of communication is highlighted by Kaplan [2]:

[...] $50 \%$ of the problems in the world result from people using the same words with different meanings. The other $50 \%$ come from people using different words with the same meaning.

For clarification of the discussion, several basic definitions of common terms used in this paper are presented below:

- Hazard - potential source of harm.

- Critical deviation - initiating (triggering) event of unwanted chain of events.

- Near-accident (incident) - event or chain of events which could have caused the unwanted (major) consequences once critical deviation occurred.

- Accident - event or chain of events which caused (major) consequences once critical deviation had occurred.

The main focus in this paper is on demands from the Norwegian offshore industry for clarification of the term 'safety barrier' and to present a new view of risk-reducing functions, as an interpretation of national regulations such as the Management Regulations from the Petroleum Safety Authority Norway (PSA). The topic is also relevant for other industries (e.g., the process industry) and application areas. The risk of major accidents is the focus.

\section{Risk reduction measures: solutions and safety barriers}

Currently in the offshore industry on the Norwegian Continental Shelf (NCS), there is a lot of discussion about barriers and the interactions between them that are greatly fostered by the Norwegian Petroleum Safety Authority's (PSA) emphasis on safety barriers. However, the question is whether safety barriers are the only measures of risk reduction. In order to start a discussion, it is necessary to have an overview of the main steps in the risk reduction process.

ISO 31000's definition [3] of risk as the "effect of uncertainty on objects" differs considerably from conventional understanding of risk in the engineering world, where it is seen as a product of probability and consequence in line with ISO 17776 [4]. It is not an objective of this paper to contribute to the understanding of risk essence; however, it may be assumed that barrier management cannot be seen as a substitute for risk management in the organization, but rather as a part of it. 
Barrier management is a part of risk management in the organization that focuses on the reduction of the likelihood of negative consequences within activities performed. An interpretation of ISO 31000 and PSA's Management Regulations sections 4 and 5 [5] would propose the following view of the barrier management process (fig. 1).

Risk management

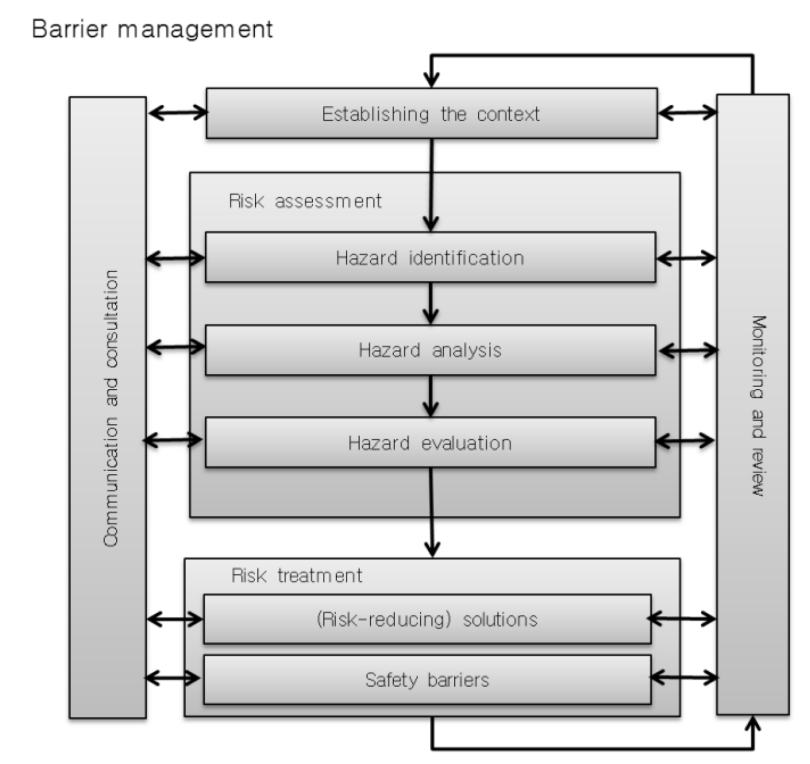

Figure 1: Barrier management process (an interpretation of ISO31000 and national regulations such as the management regulation from the Petroleum Safety Authority Norway).

The context is seen directly or indirectly as acting factors that may be important in the risk-reduction process. It includes not only requirements, standards, guidelines, acting regulations and policies, but also general experience, expert knowledge, engineering judgment, etc.

The risk assessment is intended to identify, analyse and evaluate the hazards in the activities performed. By understanding the nature of the hazard, the possible scenarios can be laid out and corresponding safety measures can be discussed accordingly. Required safety solutions and barrier functions should be derived as a result of this process.

Generally, risk treatment may be seen as a process which ensures that an acceptable risk level is achieved and maintained. To align with Petroleum Safety Authority regulations, Sections 4 and 5 of the Management Regulations [5] are incorporated: 
In reducing risk [...] the responsible party shall select technical, operational and organisational solutions that reduce the probability that harm, errors and hazard and accident situations occur.

Furthermore, barriers as mentioned in Section 5 shall be established. The solutions and barriers that have the greatest risk-reducing effect shall be chosen $[\ldots]$

Barriers shall be established that:

a) reduce the probability of failures and hazard and accident situations developing,

b) limit possible harm and disadvantages.

Two main groups of risk-reducing measures are stated: risk-reducing solutions and safety barriers.

Further assessing the definitions provided, it may be stated that solutions are the measures to reduce the likelihood of errors and hazards and accident situations occurring, i.e. preventing hazards (potential source of harm) from being realized. In other words, the solutions are used to reduce the likelihood of deviation which could initiate (trigger) an unwanted chain of events. Systems that are primary targets of these solutions may be seen as Safety Critical Systems (SCS) and will be discussed further in the paper.

Safety barriers are the measures which are selected after the risk-reducing solutions have been established and their purpose is to reduce the likelihood of failures and hazards and accident situations developing and limit the possible harm caused by an unwanted chain of events. Safety barriers are established to reduce the likelihood of the development of an unwanted chain of events when an initiating (triggering) event has already occurred, i.e. a hazard scenario has already started. The main and only function of a barrier is a safety function that is required on demand. Kecklund et al. [6] also describe safety barriers as "subsystems which can arrest the evolution of an accident through the execution of barrier functions".

While we make a distinction between the solutions and safety barriers, it is important to see both of them as one entity designed to reduce the risk within performed activities.

\section{Risk-reducing functions}

\subsection{Hierarchy of risk-reducing measures}

In line with ISO17776 [4] and its general hierarchy of risk-reducing measures, this work will propose the following risk-reducing phases as generic safety functions (fig. 2): Prevention, Detection, Control, Mitigation, Emergency Response. These functionalities act in the same sequence when placed on the chain of accident development (fig. 3).

As presented in the introduction, Norwegian Petroleum Safety Authority (PSA) regulations [5] distinguish between the solutions and barriers. Following 
the interpretation of the regulations, it is hereby proposed that the prevention function is performed by solutions in the Safety Critical Systems (SCS) while other risk-reducing functions are performed by the Safety Barrier Systems (SBS).

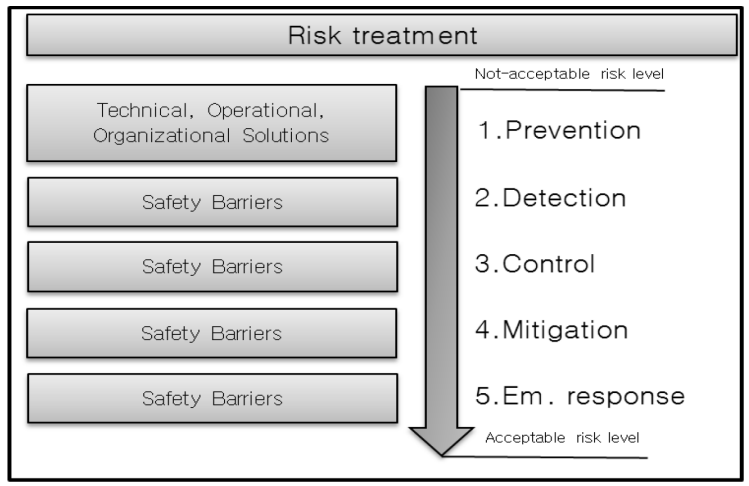

Figure 2: Risk treatment by solutions and safety barriers.

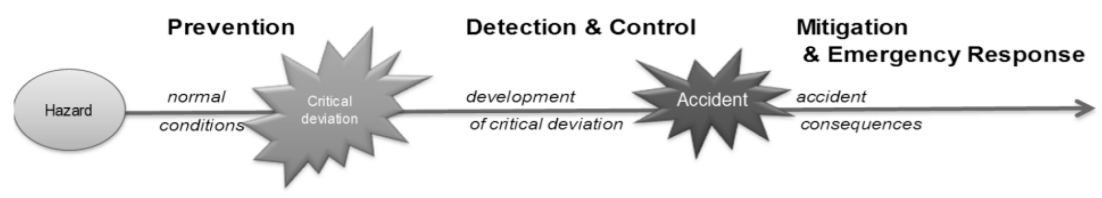

Figure 3: Accident event chain.

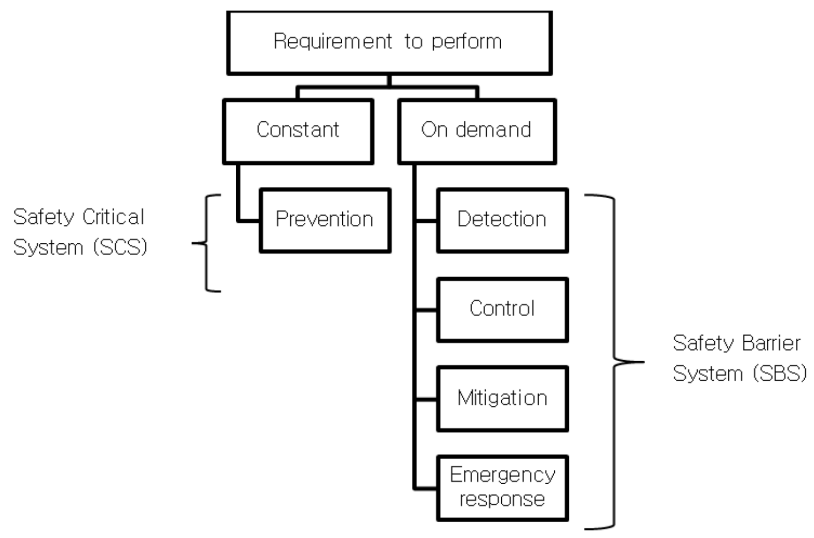

Figure 4: Requirement to perform. 
The requirement to perform indicates the actual need for the function and can be split between systems that perform the designed function continuously or at the pre-determined time intervals, and systems that are established to act on demand, where demand is seen as a critical deviation (fig. 4).

The requirement to perform should not be confused with the functionality or availability of the system. For example, the availability of a gas detector and firewall may differ, but the requirement to perform is on demand for both. A requirement to perform continuously is necessary for the measures that are directly engaged with hazards by ensuring that critical deviation will not occur. For example, a hydrocarbon-containing pipeline, pressure vessels and main process control systems are required to perform as designed continuously, because, in the case of failure, a critical deviation will immediately or subsequently occur.

\subsection{Prevention}

The prevention part embraces the inherent safety design (ISD) and process control activities by selecting such technical, operational and organizational solutions that would ensure the lowest risk level according to the ALARP principles.

The term 'prevention' can be used with several meanings. In line with ISO 13702 [7], prevention means a reduction of the likelihood of a hazardous event, and a further specified definition is used in this paper: to prevent means to reduce the likelihood that critical deviation occurs, where critical deviation is seen as an initiating event of an unwanted chain of events (hazardous event).

The practical meaning of prevention measures embraces the wide range of physical and non-physical elements, from Inherent Safe Design (ISD) and Best Available Technology (BAT) principles to main process equipment, containment vessels, piping including process-related operational actions, etc. Avoidance of a hazard is seen as a part of the ISD principles and is therefore embraced by the prevention definition used in this paper, because the likelihood of a hazardous event will be reduced if the hazard is removed (avoided).

The main function of safety critical (solution-targeted) equipment or activities is a process-, or utility-related function. These solutions may be:

- Organizational: process design principles, equipment selection guidelines, HSE strategies, etc.

- Operational: selection and improvement of operational process activities with a focus on risk-reduction.

- Technical: selection of technical equipment that shall ensure that designed process or utility functions will be performed safely and associated hazards will be prevented, i.e. the likelihood of a triggering event is reduced.) This prevention function is required to perform constantly to keep a hazard from its realization.

The prevention measures cannot be removed from the system without affecting the main process functions, i.e. they are inherent in the main process functions and have an effect constantly. If they function as designed, the 
abnormal conditions will not occur. A typical example of safety critical equipment with an applied technical solution would be hydrocarbon process piping designed to prevent leakage by adding a corrosion allowance.

Theoretically, the applied solutions would be sufficient to ensure the required safety if errors and overall uncertainty could be avoided. In the real world, however, they fail and cause the critical deviation and hazard realization to lead to an accident. Once the unwanted chain of events starts, the safety barriers are mobilized to stop its development or to limit the consequences if an accident occurs.

\subsection{Detection and control}

Detection and control systems are the safety barriers that are designed to perform the safety function only when an unwanted chain of events starts to develop. They act on demand when the prevention measures - safety-related solutions fail. A detection function ascertains the existence, presence, or appearance of critical deviation as soon as possible and serves as further input to other barrier systems as well as being necessary to activate operational barriers, i.e. human actions. The detection function itself will not stop the unwanted chain of events, but it is essential in order to enable the function of controlling barrier systems. 'To control' refers to stopping the unwanted chain of events before it develops into a major accident, and emergency shutdown or depressurization functions are the examples of such functions. While the term 'detection function' is commonly understood, the term 'control function' has several different interpretations. ISO 13702 [7] defines control as the limitation of the extent and/or duration of a hazardous event. In this paper we further specify the term and state that control means to reduce the likelihood that critical deviation will develop into a major accident once it occurs, i.e. to stop the unwanted chain of events when critical deviation occurs.

It is important to distinguish between a process control function that is a part of the safety-related solutions and one that is a function of the control barriers. Most of the process control systems are activated constantly or on a regular basis. The control function of barrier systems is activated on demand when the process or activity control is lost and the critical deviation occurs. If the barrier function to control succeeds, the development of an unwanted chain of events is stopped, i.e. the control is regained, and the near-accident event is reported. If these barriers fail, the major accident occurs, and then barriers to limit the consequences of the accident are activated.

\subsection{Mitigation and emergency response}

The definition of a major accident is not standardized, but can be seen as an escalation of an unwanted chain of events that has already caused certain consequences. It may be referred as Defined Hazard and Accident Situations (Norwegian: "Definerte Fare og Ulykkessituasjoner", DFU). Generally, a major accident is defined as an acute incident such as a major spill, fire or explosion that immediately or subsequently causes multiple serious personal injuries and/or 
loss of human lives, serious harm to the environment and/or loss of major financial assets [8].

A major accident is the result of the failure of safety-related solutions (prevention) and detection/control barrier systems. In order to limit or reduce these consequences, mitigating barrier systems are established together with emergency response measures. The successful functioning of these systems will ensure the lowest harm possible by stopping the accident escalation as soon as possible. If the mitigation and emergency response barrier systems function poorly, the accident may develop to its full potential and cause maximal damage.

Mitigation and emergency response barrier functions are designed to perform on demand, when an accident occurs and the operational control is lost. A well-known example of a mitigation system is a deluge system.

\section{Risk-reducing systems}

\subsection{Functional equipment groups}

Most oil operators on the NCS have determined groups of critical equipment and prepared the performance standards for these groups $[9,10]$. It is common to refer to these groups of equipment as barrier elements. It is well-understood that these equipment groups are tightly linked together; however, the attention to these links is often not clearly expressed. It should be stressed that a risk-reducing function can be ensured just by a fully-functioning safety system, which usually consists of various elements from different equipment groups, so the links between them are very important.

The need to know the boundaries of a system is well-expressed when the system's independence is analysed. The independence requirement is also stated in the Management Regulations of the PSA [8]. A good example of system independence could be a fire-fighting system that has its own firewater pumps designed to use just for the system in case of demand. Older installations sometimes have their firewater supply system connected to a general seawater utility used to supply seawater for the process needs. In this case, the independence requirement is not fulfilled, as the fire-fighting system's critical element - a pump - is not specifically designed for the safety-function only. The actual safety system should not be seen as only the equipment group based on its functionality, but more as the combination of these acting in defence against hazard realization.

\subsection{Hazard and three lines of defence}

Hazard identification is the first step of the process to identify existing or establish new barriers and should be the integral part of the barrier management system. It is important to note that hazard identification activities should be continuously performed and existing hazard lists should be updated. The HAZID process is a good example used in the industry for hazard identification. It is 
important to select a proper scale of hazard analysis, for example: Hydrocarbon leak in area no. xxx, Dropped objects, Collision with ship, etc.

Once site-specific hazard scenarios have been laid out, each of them can be looked at from the time perspective (fig. 5). It is possible to distinguish between three major phases when looking at the timeline of any hazard scenario: normal conditions, abnormal condition such as the result of critical deviation, and the accident phase. Some systems can perform more than one main function, depending on the hazard scenario.

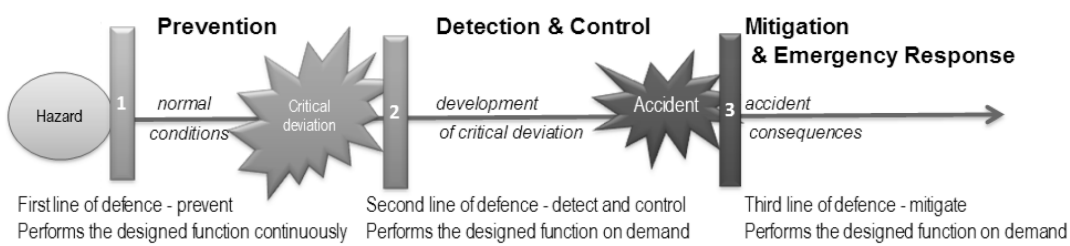

Figure 5: Three lines of defence.

\subsection{First line of defence - Safety Critical System (SCS) as prevention system}

A Safety Critical System (SCS) is a system with applied technical, operational and organizational solutions designed to prevent the realization of a potential source of harm inherent in the activities. The requirement to perform is constant. In the case of a system's failure, a critical deviation will occur and start the development of an unwanted chain of events.

The SCS can be composed just of the technical solutions part, or just of operational solutions, or of a combination of both (fig. 6). A possible example of an SCS could be a system to prevent the loss of containment, a system to prevent process deviations (process safety), or a system to prevent the loss of structural integrity.

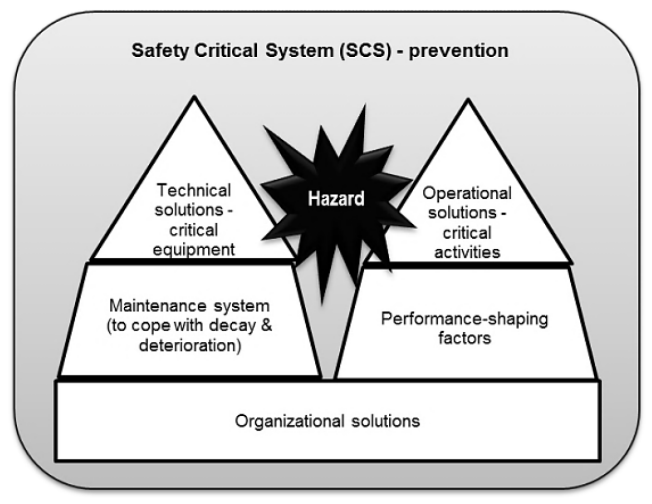

Figure 6: $\quad$ Safety Critical System (SCS). 
- Organizational: strategies and principles under which the system is built.

- Operational: operational process activities performed by the operator. Performance-shaping factors should be known in order to estimate the likelihood of human error.

- Technical: process equipment and related auxiliary equipment that is subjected to a specific hazard scenario and should be designed or/and selected according to ALARP principles. The maintenance system is established to ensure the functional and safety requirements over the asset's lifetime. Performance-shaped factors related to operational maintenance activities are treated as a part of the maintenance system.

The SCS and associated elements cannot be removed from the facility or process system without affecting that process imminently or subsequently.

\subsection{Second and third lines of defences - Safety Barrier Systems (SBS)}

It is important to see a barrier as an actually established measure that is able to prevent or stop the unwanted chain of events once the initiating event is triggered. Safety principles for nuclear power plants distinguish barriers as physical measures only, while other types of protection are recognized but not defined as barriers [11]. Organizational safety measures such as procedures, strategies, guidelines, requirements, etc. can be seen as a regulatory basis that is used to establish the barriers, but they are not barriers in themselves. There are a lot of intentions to name them as organizational barriers; however, they cannot be seen as actual barriers that would be able to perform in the case of need. Either physical equipment - a technical barrier - or human actions - an operational barrier - can actually stop the unwanted chain of events that has already started due to the specific critical deviation or mitigate the consequences of it.

A Safety Barrier System (SBS) is comprised of technical and operational barriers (figs. 7 and 8). Some of the automatized system will only have the technical barrier part, while manually-activated or manually-operated systems will require appropriate human actions - an operational barrier. There can also be systems based only on operational barriers.

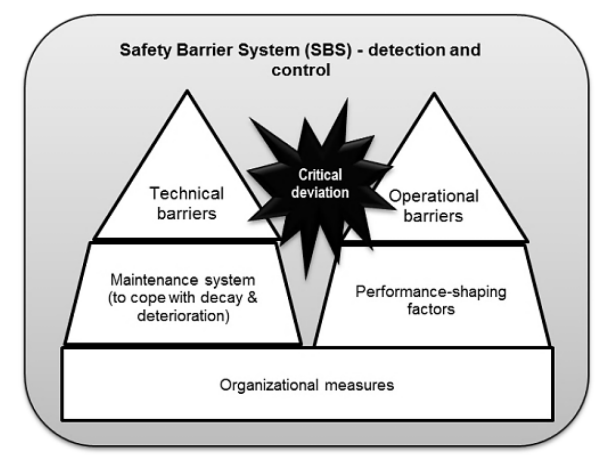

Figure 7: Safety Barrier System - detection and control. 


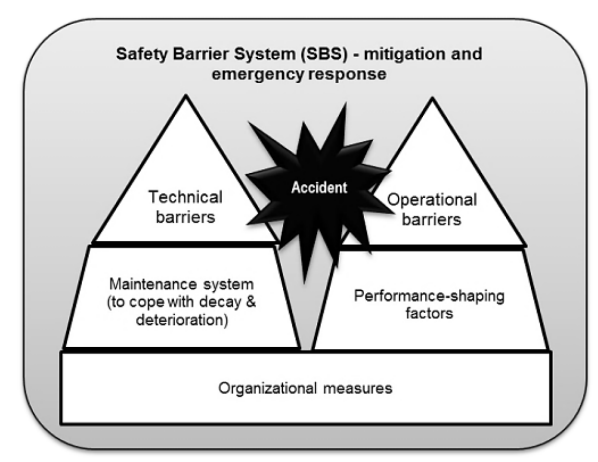

Figure 8: $\quad$ Safety Barrier System - mitigation and emergency response.

The technical part of a Safety Barrier System (SBS) is comprised of a technical barrier, the maintenance system, and organizational measures that are used as a basis for the establishment and follow-up of the barrier system. A technical barrier is a physical element that is established to perform safety functions related to stopping the unwanted chain of events when it has been started: detection, control, mitigation or emergency response.

The Safety Barrier System (SBS) can theoretically be removed from the facility as it functions on demand after the critical deviation has occurred. Then process activities could theoretically still be carried out, assuming that no critical deviations would happen; however, in the case where they did occur, the potential consequences would be extreme.

To ensure the required functionality of technical barriers, the maintenance and follow-up activities should be performed by establishing a maintenance programme. For example, the automatic safety system is one of the main technical barriers; therefore function testing and demand monitoring should be established. This refers to the field of functional safety and is governed by IEC 61511 [12] and IEC 61508 standards [13]. Other technical barriers should be analysed, the criticality and failure/fault modes of their elements shall be determined and appropriate maintenance activities should be undertaken. All technical barrier elements should be tagged and marked accordingly in the general maintenance system of the facilities. In addition, the maintenance system should incorporate the analysis of human factors and the performance-shaping factors of operational maintenance activities. Industry examples show that maintenance system and barrier follow-up is enabled through the creation of performance standards - the functional requirement list of each barrier system $[14,15]$. It must be noted, however, that the boundaries of barrier definition used in most companies differ from those presented in this paper.

The operational part of a Safety Barrier System (SBS) consists of an operational barrier, the performance-shaping factors and organizational measures that are used as a basis to establish the system itself. An operational barrier can be seen as determined specific actions that shall be carried out in the case of critical deviation to prevent or to stop the development of an unwanted chain of events, for example, a manual activation of an evacuation alarm, etc. 
An operational barrier is defined as the specific safety activities performed by human operator therefore human factors affect it. The UK Health and Safety Executive defines human factors as "environmental, organizational and job factors, and human and individual characteristics which influence behaviour at work in a way which can affect health and safety" [16]. Explicitly defined human factors may be seen as Performance-Shaping Factors (PSF) and are used to model human behaviour as the underlying causes of abnormal performance [17]. It must be noted that PSF are explicitly used to describe the influence on human performance [18] and should not be directly referred to as the performance of technical equipment. Technical equipment is affected by maintenance actions which are again influenced by PSF [19]. However, the PSF of maintenance activities should be seen as an integral part of the maintenance system, and maintenance activities should be distinguished from the operational safety barrier concept that embraces specified safety actions in the case of abnormal situations.

\subsection{Generic work flow diagram}

The generic work flow diagram given in fig. 9 embraces the concept of solutions and safety barriers presented in this paper.

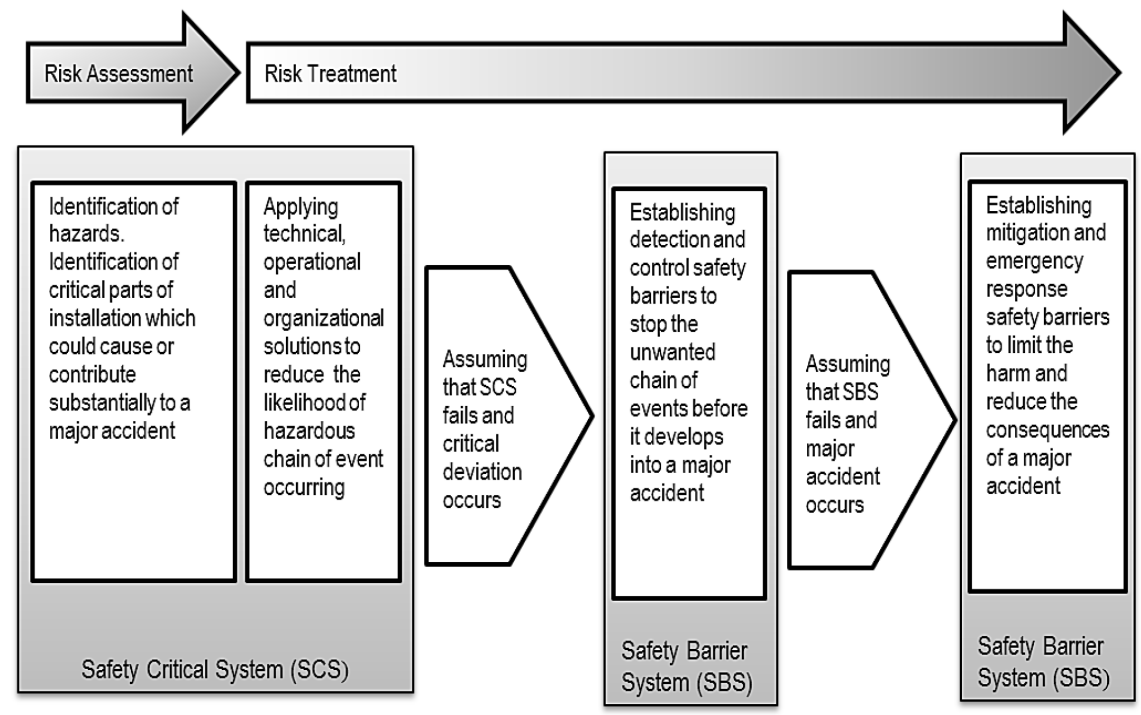

Figure 9: Generic work flow.

It presents the general scheme of hazard identification and the treatment process. A facility-specific Barrier Map can be derived to show risk-reducing measures - solutions and barriers - as put in place to manage the hazards (fig. 10). 

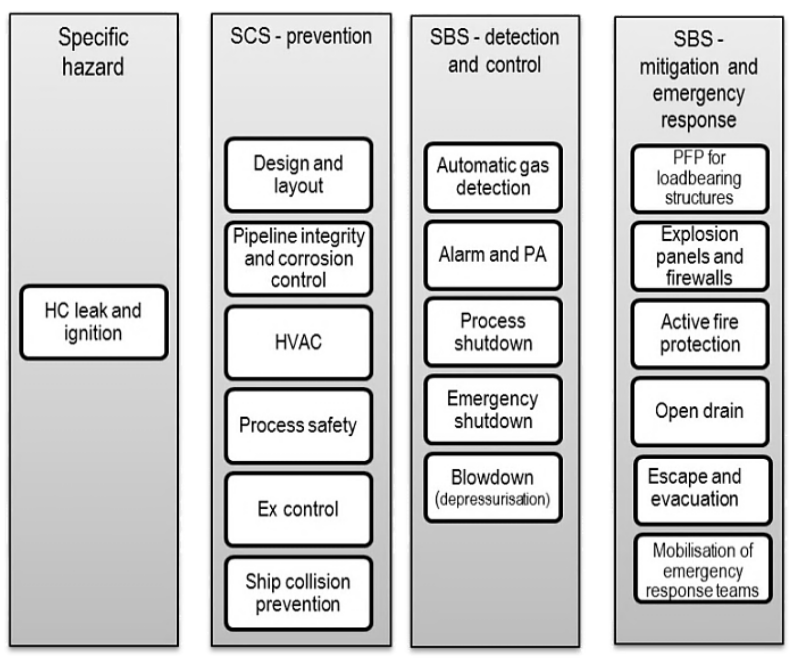

Figure 10: Example of Barrier Map of facility.

\subsection{Comparison between SCS and SBS}

The components of these systems may be named Safety Critical Elements (SCE) and Safety Barrier Elements (SBE). Currently the industry uses the term 'SCE' to define all the elements that are "such parts of the installation [...] which could cause and contribute substantially to a major accident or a purpose of which is to prevent or limit the effect of a major accident" [20]. According to the concept presented in this paper, the new boundaries of the SCE would embrace parts of the installation which could cause or contribute to a major accident. Safety Barrier Elements - SBE - would embrace the elements of independent safety systems that are installed only for the safety function and in the case of failure will stop the accident development or limit the effect of an accident as a Safety Barrier System (SBS). Table 1 below summarizes the main differences between Safety Critical System (SCS) and Safety Barrier Systems (SBS).

Table 1: SCS and SBS comparison.

\section{Safety Critical System (SCS)}

Technical, operational and org. solutions applied to process, utilities, structural, etc. elements to reduce risk within them

Reduces the likelihood of critical conditions occurring

\section{Requirement to perform - constant (normal} conditions)

Cannot be removed without affecting process

\section{Safety Barrier System (SBS)}

Independent system designed only for risk-reducing functions

Reduces the likelihood of critical conditions developing and limits the harm

Requirement to perform - on demand (abnormal conditions)

Can be removed without affecting process 


\subsection{Comparison between generic safety functions}

Sklet [1] uses the Occupational Accident Research Unit (OARU) process model [21]. The accident is divided into three phases: the initial phase, the concluding phase, and the injury phase. The generic safety functions are intended to stop the chain of events before it develops into the next phase. A comparison reveals the different meanings for the same terms used by researchers and standards (fig. 10). For example, in the classification of Hollnagel [22], both 'control' and 'mitigation' are treated as protection, while 'prevention' also embraces the control measures. In the classification suggested in the ARAMIS-project [23], both functions 'avoid' and 'prevent' correspond to the function prevention according to [1]. The last row in the figure presents the boundaries of definitions used in this paper (in line with ISO 17776 [4]).

\begin{tabular}{|c|c|c|c|c|c|c|}
\hline \multicolumn{6}{|c|}{ Accident sequence } & \\
\hline \multicolumn{2}{|c|}{ Normal conditions } & Initial phas & Concluding phase & \multicolumn{2}{|c|}{ Injury phase } & \\
\hline \multicolumn{3}{|c|}{ Lack of control } & of control & exposure & & \\
\hline \multicolumn{3}{|c|}{ Prevent } & \multicolumn{3}{|c|}{ Protect } & [22] \\
\hline \multicolumn{2}{|c|}{ Prevent } & \multicolumn{2}{|c|}{ Control } & \multicolumn{2}{|c|}{ Mitigate } & [1] \\
\hline Avoid & Prevent & \multicolumn{2}{|c|}{ Control } & \multicolumn{2}{|c|}{ Protect } & [23] \\
\hline \multicolumn{2}{|c|}{ Prevent } & Detect & Control & Mitigate & $\begin{array}{c}\text { Emergency } \\
\text { response }\end{array}$ & $\begin{array}{l}\text { [4] (used as a } \\
\text { basis in this } \\
\text { paper) }\end{array}$ \\
\hline
\end{tabular}

Figure 11: Generic safety functions in a process model, adapted from [1].

\subsection{Three lines of defence as a model for risk communication}

A typical process model approach divides the accident sequence into several phases, and analyses the defence elements that may stop the unwanted chain of events. A qualitative process model is presented by combining the accident timeline and the proposed risk-reducing systems (fig. 12). It allows the actual established measures to be seen against the specific hazard scenario in the various phases of the potential accident timeline.

Such a sequential accident model may also be used as a basis to analyse particular risk-reducing functions in detail, for example, incorporating fault or event trees $[24,25]$. In the generic example, the event tree model could be used to lay down the systems used in the specific hazard scenario, and then a fault tree analysis could be performed for each part (fig. 13). 


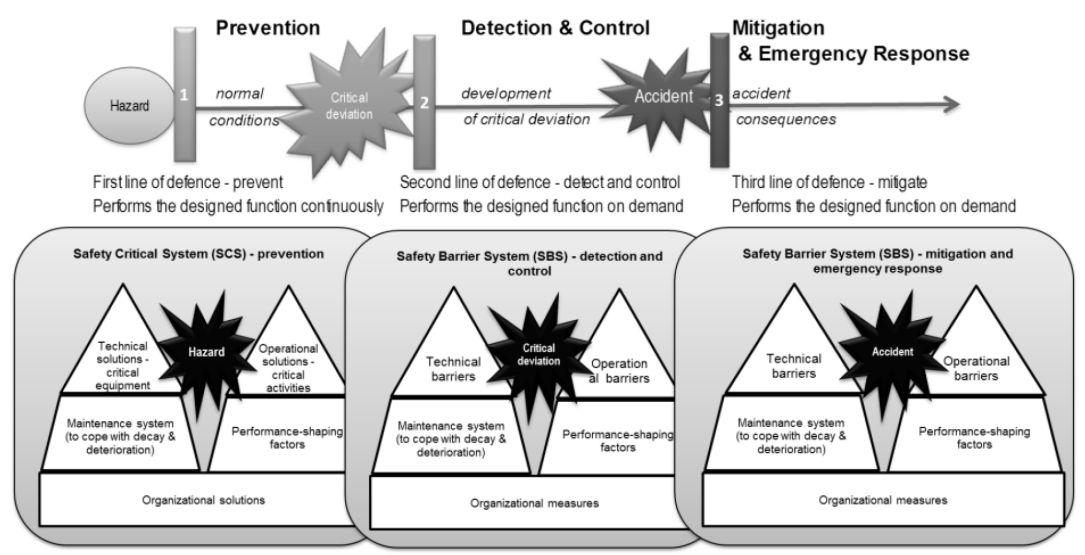

Figure 12: Three lines of defence model.

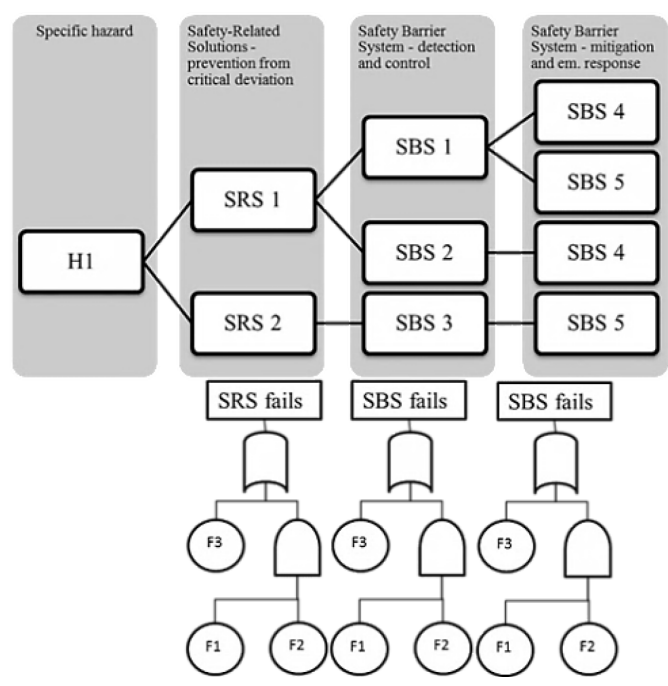

Figure 13: Generic example of using event and fault trees.

In [8] it is stated that "personnel shall be aware of what barriers have been established and which function they are intended to fulfil", and such a model may be used as a first step for broader communication about the safety barriers and their role in arresting the accident's escalation. Therefore such a model may be valuable in risk communication, where its simplicity could be well-accepted by non-technical safety personnel without the requirement for special knowledge. 


\section{Defence-in-depth}

\subsection{Defence-in-depth conception}

The concept of defence-in-depth was developed within the nuclear industry and constitutes the basis for the discussion of safety barriers. IAEA (1999: 17), [11], describes the defence-in-depth principle in the following way:

To compensate for potential human and mechanical failures, a defence in depth concept is implemented, centred on several levels of protection including successive barriers preventing the release of radioactive material to the environment. The concept includes protection of the barriers by averting damage to the plant and to the barriers themselves. It includes further measures to protect the public and the environment from harm in case these barriers are not fully effective.

All safety activities within the nuclear industry are subjected to overlapping layers of protection, so that if an error occurs it will be altered or escalation will be stopped without causing harm. The idea of multiple levels of protection is the core principle of defence-in-depth and it aligns with Swiss cheese model [26], where an organization's defences against error are modelled as a series of layers. Following these concepts, Safety Critical Systems (SCS) and Safety Barrier Systems (SBS) are shown as generic safety layers (fig. 14).

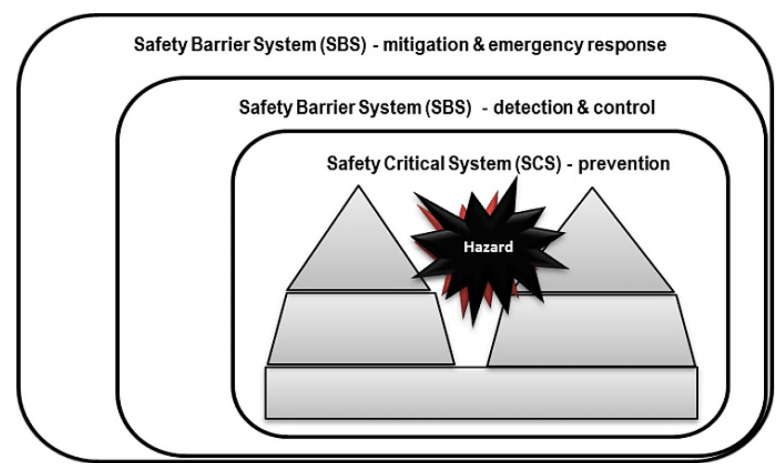

Figure 14: SCS and SBS as generic safety layers.

Based on the multiple levels of protection concept, known risk assessment methods such as Layer of Protection Analysis (LOPA) are widely used [27, 28]. Although a layer of protection is currently seen as a synonym to a barrier, it is different according to the re-defined concept of barrier boundaries presented in this paper. Both Safety Critical Systems (SCS) and Safety Barrier Systems (SBS) create layers of protection but are distinguished according to the requirement to perform and the nature of the system. The SCS embrace the layers of protection that are required to perform constantly and have a process-related main function, while the SBS are treated as additional layers of protection that perform on demand and are established only for safety functions (fig. 15). 


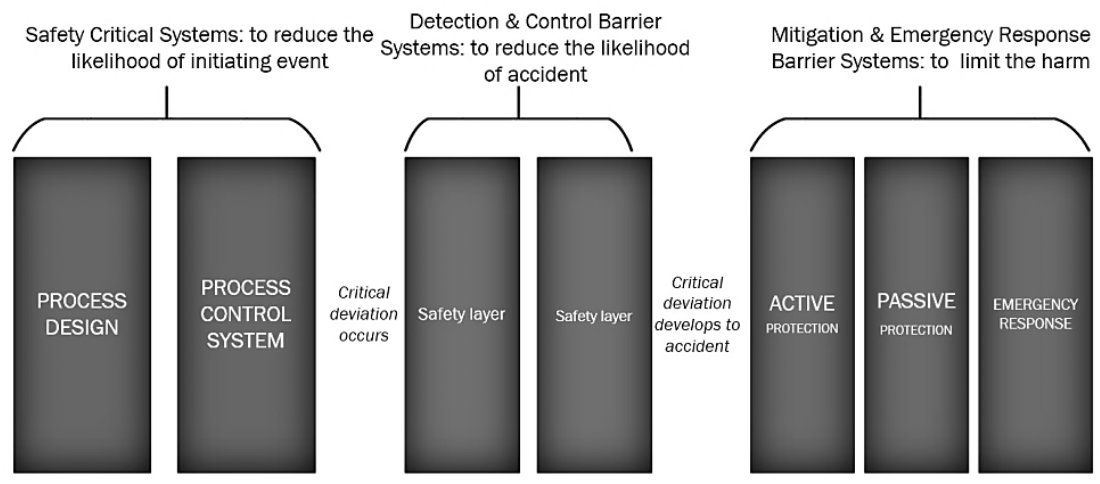

Figure 15: SCS and SBS as layers of protection.

\section{Conclusions}

Kaplan [2] describes a case where risk analysts worked for four years trying to define the word 'risk'. They finally gave up, saying that maybe "it is better not to define risk". It was proposed that each author be allowed to define it in his own way, only being asked to clarify what way that is. Accordingly, in order to improve risk communication among the involved parties, it is important to focus more on the clarity than the verbal interpretations of the safety barrier concept.

"Finally, making the decision is not the end of the job. It's necessary to get the decision accepted and implemented. For that we need the support of the people affected by it. That means risk communication, and decision communication. For that to take place, it's crucial that we have words that we all understand and use in the same way," [2].

Based on the synthesis of [4], the PSA regulations and common features of the terms found in the scientific literature, the concepts of Safety-Related Solutions (SRS) and Safety Barrier Systems (SBS) are proposed as a basis for further discussion of risk-reducing measures in the industrial activities.

Sklet [1] notes that "such a broad definition undermines the concept of barrier as some claim that almost everything may be considered as a barrier" and suggests to distinguish between the measures "that may prevent, control, or mitigate the event sequence or accident scenario directly".

Correspondingly, prevention, detection/control, and mitigation/emergency response systems have been introduced and described. Aligning with the PSA regulations, the safety-related solutions have been separated from safety barriers and systematically described. Links between technical, operational and organizational elements have been proposed incorporating maintenance activities and human factors, such as performance-shaping factors. 
In addition, the paper proposes a model for communication about riskreducing measures: safety solutions and barriers. The results may be useful for the Norwegian oil industry in its effort to fulfil the requirements of the PSA.

\section{References}

[1] Sklet, S., "Safety barriers: Definition, classification, and performance," Journal of loss prevention in the process industries, vol. 19, pp. 494-506, 2006.

[2] Kaplan, S., "The words of risk analysis”, Risk analysis, vol. 17, pp. 407-417, 1997.

[3] ISO 31000, Risk management. Principles and guidelines on implementation, ed: Geneva: International Organization for Standardization, 2009.

[4] ISO 17776, Petroleum and natural gas industries. Offshore production installations. Guidance on tools and techniques for hazard identification and risk assessment, ed.: Geneva: International Organization for Standardization, 2000.

[5] PSA, Regulations relating to management in the petroleum activities (The Management Regulations), ed.: Norway, Stavanger: Petroleum Safety Authority, 2014.

[6] Kecklund, L. J., Edland, A., Wedin, P. and Svenson, O., "Safety barrier function analysis in a process industry: a nuclear power application”, International journal of industrial ergonomics, vol. 17, pp. 275-284, 1996.

[7] ISO 13702, Petroleum and natural gas industries. Control and mitigation of fires and explosions on offshore production installations, ed.: Geneva: International Organization for Standardization, 1999.

[8] PSA, Guidelines to regulations relating to management in the petroleum activities (The management regulations), ed.: Norway, Stavanger: Petroleum Safety Authority, 2014.

[9] Statoil, Performance standards for safety systems and barriers - offshore. Technical and professional requirement, TR1055, Final Ver. 4.02, valid from 2012-02-09, ed.: Governing document of company, 2012.

[10] BP, General safety strategy and performance standards for technical barriers, ed.: Governing document of company, 2013.

[11] IAEA, Basic safety principles for nuclear power plants: 75-INSAG-3, rev.1, ed.: Vienna: The International Atomic Energy Agency, 1999.

[12] IEC 61511-1, Functional safety - Safety instrumented systems for the process industry sector - Part 1: Framework, definitions, system, hardware and software requirements, ed.: Geneva: International Electrotechnical Commission, 2004.

[13] IEC 61508, in Part 1-7 Functional safety of electrical/ electronic/programmable electronic safety-related systems, ed.: Geneva: International Electrotechnical Commission, 2010.

[14] Firing, F.L., Ostby, E., Ingvarson, J. and Strom, O., “TTS-the systematic and efficient approach to define maintain and demonstrate safety 
performance on complex hydrocarbon processing facilities", in Offshore Technology Conference, 2011.

[15] Thomassen, O. and Sørum, M., "Mapping and monitoring the technical safety level", in SPE International Conference on Health Safety and Environment in Oil and Gas Exploration and Production, 2002.

[16] HSG48, Reducing error and influencing behaviour, ed.: UK Health and Safety Executive, 2009.

[17] El-Ladan, S. B. and Turan, O., "Human reliability analysis - Taxonomy and praxes of human entropy boundary conditions for marine and offshore applications”, Reliability Engineering \& System Safety, vol. 98, pp. 43-54, 2// 2012.

[18] Musharraf, M., Hassan, J., Khan, F., Veitch, B., MacKinnon, S. and Imtiaz, S., "Human reliability assessment during offshore emergency conditions", Safety Science, vol. 59, pp. 19-27, 11// 2013.

[19] Toriizuka, T., "Application of performance shaping factor (PSF) for work improvement in industrial plant maintenance tasks", International journal of industrial ergonomics, vol. 28, pp. 225-236, 2001.

[20] Dhar, R., "Performance standards for safety critical elements - are we doing enough!” in SPE European Health Safety and Environmental Conference in Oil and Gas Exploration and Production, 2011.

[21] Kjellen, U. and Larsson, T. J., "Investigating accidents and reducing risks - a dynamic approach", Journal of occupational accidents, vol. 3, pp. 129-140, 1981.

[22] Hollnagel, E., Barriers and accident prevention: Ashgate Publishing, Ltd., 2004.

[23] Duijm, N., Madsen, M., Andersen, H., Hale, A., Goossens, L., Londiche, H., et al., "Assessing the effect of safety management efficiency on industrial risk", in European Safety and Reliability Conference (ESREL 2003), 2003, pp. 575-581.

[24] Xue, L., Fan, J., Rausand, M., and Zhang, L., "A safety barrier-based accident model for offshore drilling blowouts", Journal of loss prevention in the process industries, vol. 26, pp. 164-171, 2013.

[25] Kujath, M., Amyotte, P., and Khan, F., "A conceptual offshore oil and gas process accident model", Journal of loss prevention in the process industries, vol. 23, pp. 323-330, 2010.

[26] Reason, J., "The contribution of latent human failures to the breakdown of complex systems", Philosophical transactions of the Royal Society of London., B, Biological sciences, vol. 327, pp. 475-484, 1990.

[27] Gowland, R., "The accidental risk assessment methodology for industries (ARAMIS)/layer of protection analysis (LOPA) methodology: A step forward towards convergent practices in risk assessment?" Journal of hazardous materials, vol. 130, pp. 307-310, 2006.

[28] Summers, A. E., "Introduction to layers of protection analysis", Journal of hazardous materials, vol. 104, pp. 163-168, 2003. 